\title{
Defecography by digital radiography: experience in clinical practice $^{*}$
}

\author{
Defecografia por radiologia digital: experiência na prática clínica
}

Amanda Nogueira de Sá Gonçalves ${ }^{1}$, Marco Aurélio Sousa Sala ${ }^{1}$, Rodrigo Ciotola Bruno ${ }^{2}$, José Alberto Cunha Xavier $^{3}$, João Mauricio Canavezi Indiani ${ }^{1}$, Marcelo Fontalvo Martin ${ }^{1}$, Paulo Maurício Chagas Bruno ${ }^{2}$, Marcelo Souto Nacif ${ }^{4}$

Gonçalves ANS, Sala MAS, Bruno RC, Xavier JAC, Indiani JMC, Martin MF, Bruno PMC, Nacif MS. Defecography by digital radiography: experience in clinical practice. Radiol Bras. 2016 Nov/Dez;49(6):376-381.

Abstract Objective: The objective of this study was to profile patients who undergo defecography, by age and gender, as well as to describe the main imaging and diagnostic findings in this population.

Materials and Methods: This was a retrospective, descriptive study of 39 patients, conducted between January 2012 and February 2014. The patients were evaluated in terms of age, gender, and diagnosis. They were stratified by age, and continuous variables are expressed as mean \pm standard deviation. All possible quantitative defecography variables were evaluated, including rectal evacuation, perineal descent, and measures of the anal canal.

Results: The majority (95\%) of the patients were female. Patient ages ranged from 18 to 82 years (mean age, $52 \pm 13$ years): 10 patients were under 40 years of age; 18 were between 40 and 60 years of age; and 11 were over 60 years of age. All 39 of the patients evaluated had abnormal radiological findings. The most prevalent diagnoses were rectocele (in $77 \%$ ) and enterocele (in $38 \%$ ). Less prevalent diagnoses were vaginal prolapse, uterine prolapse, and Meckel's diverticulum (in $2 \%$, for all).

Conclusion: Although defecography is performed more often in women, both genders can benefit from the test. Defecography can be performed in order to detect complex disorders such as uterine and rectal prolapse, as well as to detect basic clinical conditions such as rectocele or enterocele.

Keywords: Defecography; Constipation; Rectocele; Rectal prolapse.

Resu mo Objetivo: Este estudo tem por objetivo descrever o perfil da população que se submeteu a exame de defecografia, de acordo com a faixa etária e sexo do paciente, bem como os principais achados e diagnósticos de imagem nesta população.

Materiais e Métodos: Estudo retrospectivo e descritivo com 39 pacientes realizado entre janeiro de 2012 e fevereiro de 2014 . Os pacientes foram avaliados quanto a idade, sexo e os diagnósticos encontrados. Foram divididos por idade, e as variáveis contínuas são expressas como média \pm desvio-padrão. Todas as quantificações possíveis em defecografia foram realizadas neste trabalho, incluindo esvaziamento da ampola retal, descenso perineal e as medidas do canal anal.

Resultados: Dos 39 pacientes estudados, todos apresentaram alterações radiológicas, sendo a maioria do sexo feminino (95\%). 0 mais novo tinha 18 anos e o mais velho, 82 anos (idade média de $52 \pm 13$ anos). Dez pacientes tinham menos de 40 anos, 18 tinham entre 40 e 60 anos e 11 pacientes tinham mais do que 60 anos. Os diagnósticos mais prevalentes foram retocele anterior (77\%) e enterocele (38\%). Os menos frequentes foram prolapso vaginal (2\%), prolapso uterino (2\%) e divertículo de Meckel (2\%).

Conclusão: As mulheres realizam mais exames de defecografia, porém ambos os gêneros se beneficiam deste estudo. A defecografia é capaz de detectar causas complexas de distúrbio da defecação como prolapso vaginal, uterino e retal, e pode ser utilizada em condições clínicas mais simples como a avaliação de retocele ou enterocele.

Unitermos: Defecografia; Constipação intestinal; Retocele; Prolapso retal.

* Study conducted at the Unidade de Radiologia Clínica (URC), São José dos Campos, SP, Brazil.

1. Physician at the Unidade de Radiologia Clínica (URC) and at the Hospital Vivalle/ D'Or/São Luiz, São José dos Campos, SP, Brazil.

2. General Surgeon and Coloproctologist at the Hospital Vivalle/D'Or/São Luiz, São José dos Campos, SP, Brazil.

3. General Surgeon and Coloproctologist at the Hospital Pio XII, São José dos Campos, SP, Brazil.

4. Adjunct Professor in the Radiology Department of the Faculdade de Medicina da Universidade Federal Fluminense (UFF), Niterói, RJ, Brazil.

Mailing address: Dr. Marcelo Souto Nacif. Rua Barão de Cocais, 324, Bosque Imperial. São Paulo, SP, Brazil, 12242-042. E-mail: msnacif@gmail.com/www.msnacif. med.br.

\section{INTRODUCTION}

Defecography is a radiographic method for the study of defecation that provides images of morphological and functional changes in the pelvis and anorectal segment. It is a valuable method for the study of the physiology of the pelvic dynamics of colorectal disorders such as dyskinesia, constipation, fecal incontinence, anal pain, and tenesmus ${ }^{(1)}$.

The first reports of radiological studies of the pelvic dynamics during evacuation were by Lennart Walldén, in 1952.

Received June 4, 2015. Accepted after revision October 30, 2015. 
However, it was only after the studies conducted by Mathieu et al., in 1984, that the test sparked interest within the medical community ${ }^{(2)}$.

Anorectal disorders represent a common clinical problem and have a great impact on the quality of life of the patients $^{(3)}$. The physical examination is often difficult and provides few details, failing to identify pelvic organ prolapse in $45-90 \%$ of cases. In addition, the physical examination can fail to diagnose associated prolapses. Multiple compartment dysfunction is common and changes the surgical approach; if undiagnosed, such dysfunction leads to symptom recurrence $^{(1)}$.

Although there is a considerable variation among treatment facilities in relation to the examination technique employed, most employ a technique based on the method standardized by Mahieu et al. ${ }^{(2)}$.

There have been few studies focusing on defecography tests that involve the use of conventional radiography. Therefore, the aim of the present study was to describe the profile of a population undergoing defecography, as well as the main findings of and diagnoses made from imaging studies in this population.

\section{MATERIALS AND METHODS}

\section{Selection of patients}

This was a descriptive, retrospective study, using data collected between January 2012 and February 2014. A total of 39 defecography tests by digital radiography, performed at the Unidade de Radiologia Clínica (URC), in the city of São José dos Campos, SP, Brazil, were selected for analysis.

\section{Protocol for defecography by conventional radiography}

In the initial evaluation, a complete patient history should be taken in order to investigate previous intestinal diseases, pelvic or abdominal surgery, parity, and clinical condition. The procedure must be clearly explained to the patient, with the intention to obtain full cooperation and an ideal end result.

Approximately 2 hours before the exam, the patient receives $400 \mathrm{~mL}$ of pulverized oral contrast, in order to visualize the entire small intestine. The patient is then placed in the left lateral decubitus position for rectal administration of a barium paste to a volume of approximately $200 \mathrm{~mL}$ or until the patient reports discomfort (sensation of rectal fullness). The pulverized contrast should be standardized as to its density and viscosity ${ }^{(1)}$.

A $2 \mathrm{~cm}$-high rectangular marker is placed over the pubis, in order to facilitate the identification of bone repair and serve as a reference for the quantitative analysis. Another, tubular marker (saline applicator), approximately $0.5 \mathrm{~cm}$ in diameter and filled with barium, is adhered to the first, running from the pubis to the sacrum and secured at both ends with hypoallergenic tape (Figure 1A). It is important that this marker is well adhered to the skin and the perianal region, so that the position of the anal canal is well recognized.

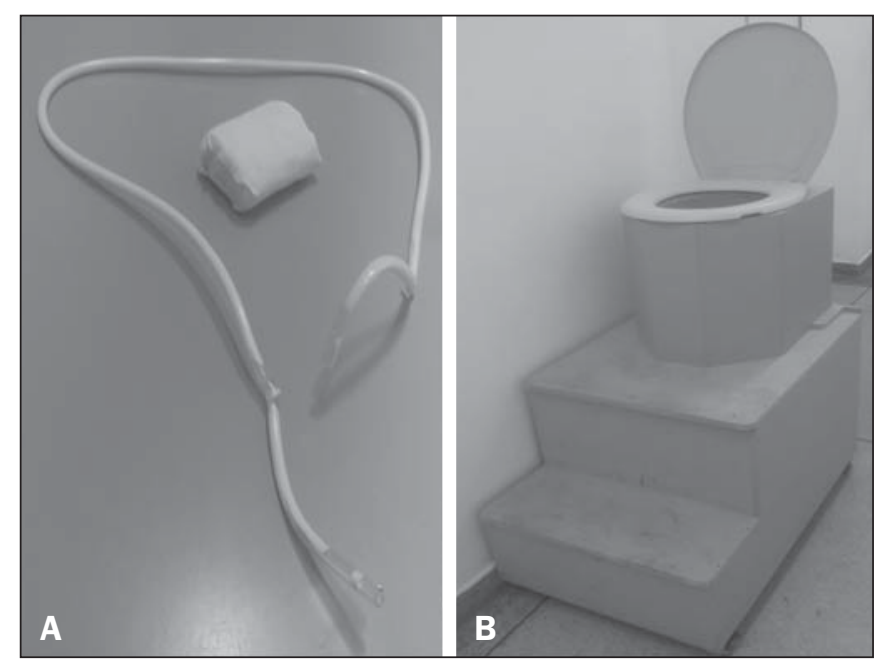

Figure 1. Pubococcygeus marker used for reference during the exam $(\mathbf{A})$ and the adaptation of equipment to perform the defecography (B) used at our facility.

The patient then sits on a radiolucent seat and remains in that position throughout the test. A wooden table that provides good exposure of the rectum is used for support (Figure 1B).

The $\mathrm{X}$-rays are taken while the patient sits on the seat, arms folded across the chest, in the following incidences: at rest, during contraction, during the Valsalva maneuver, during evacuation, and during post-evacuation (Figure 2). It is important to impress upon the patient the importance of remaining in position, inclining the thorax, during the $\mathrm{X}$ ray exposures.

\section{Analysis of demographic, clinical, and defecography data}

Patients were stratified, by age, into three groups: young adult ( $<40$ years of age), comprising $10(25.64 \%)$ of the 39 patients; adult (40-60 years of age), comprising $18(46.16 \%)$; and elderly (> 60 years of age), comprising $11(28.20 \%)$.

All images were archived in the DICOM format and transferred to commercially available workstations: Leonardo (Siemens AG Medical Solutions; Munich, Germany) and OsiriX (Pixmeo SARL; Geneva, Switzerland). Cases in which the examinations did not follow the protocol were excluded, as were those in which the images were not archived correctly. All images were analyzed, case by case, by two expert physicians working independently. Disagreements were resolved by consensus.

The following measurements were considered:

- Anorectal angle: The anorectal angle is formed by a straight line passing through the axis of the anal canal and another that passes through the posterior wall of the rectum (Figure 3A). Under normal conditions, it is expected that the mean anorectal angle, at rest, is $95^{\circ}$, with a physiological variation of $65-100^{\circ(4)}$. With contraction, the angle should decrease and become more acute, whereas it should increase, becoming more obtuse, due to straightening of the rectum, during evacuation.

- Perineal descent: First, a line is drawn from the pubic bone to the tip of the coccyx. The perineal descent is a line 

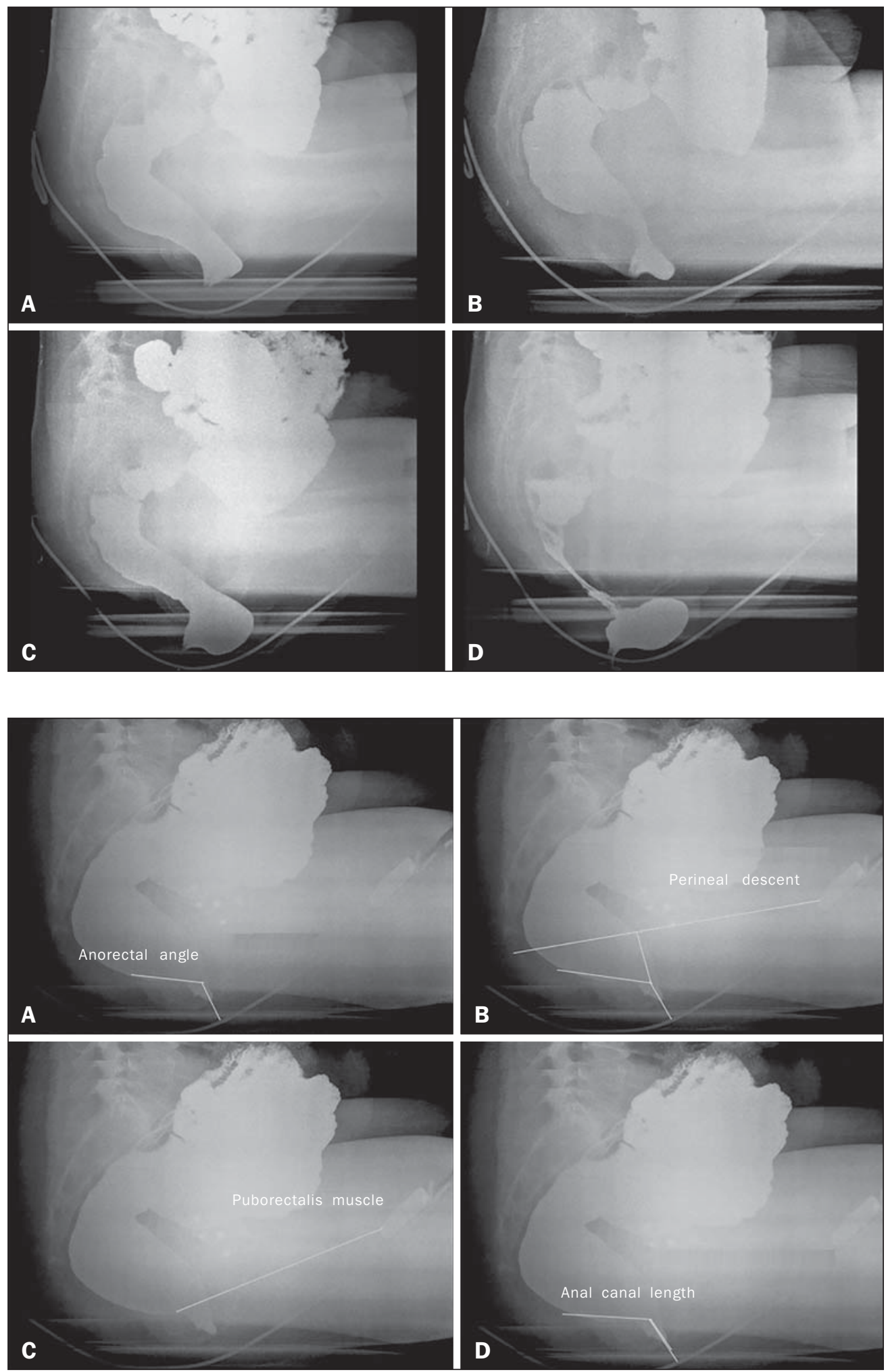

Figure 2. Maneuvers during the defecography examination: at rest $(\mathbf{A})$, during contraction (B), during the Valsalva maneuver (C), and during evacuation (D). Note the anterior rectocele during evacuation. running the anorectal junction to a point at $90^{\circ}$ on the pubococcygeal line (Figure 3B).

- Puborectalis muscle: This muscle is measured on a straight line that extends from the lower posterior portion of the pubic symphysis (landmark) to the point of greatest inflection in the posterior rectal wall (Figure 3C). The muscle typically relaxes, thus lengthening, during evacuation ${ }^{(1)}$.
- Anal canal length: The length of the anal canal is defined as the distance between the anal verge and the anorectal junction. The reference range is $2.5-4.0 \mathrm{~cm}$ (Figure 3D).

- Opening of the anal canal: The opening of the anal canal is measured in the anteroposterior direction, in centimeters. The reference value is $1.5 \mathrm{~cm}$ during evacuation ${ }^{(5)}$. It is important to take this measurement at rest, during contraction, 
and during evacuation, as well as to draw comparisons among the measurements, evaluating the capacity for contraction and relaxation. It is considered normal for there to be a difference of up to $3.5 \mathrm{~cm}$ between the measurement during evacuation and that obtained at rest ${ }^{(5)}$.

- Degree of rectal emptying: To determine the degree of rectal emptying, $\mathrm{X}$-rays are obtained at rest and at one minute after evacuation. The degree of rectal emptying is calculated by subtracting the area measured in contrast-enhanced images before and after evacuation, using the following formula:

$\%$ of emptying $=$ initial volume - final volume $\times 100$

We consider $>80 \%$ emptying to be the reference value. Involuntary losses during the examination must be registered in order to characterize fecal incontinence.

\section{Statistical analysis}

Continuous variables are expressed as mean \pm standard deviation, and categorical variables are expressed as number and percentage, according to the situation. Comparisons among the age groups were made by analysis of variance with Bonferroni correction. The statistical analysis was performed with Stata ${ }^{\circledR}$, version 12.0 (StataCorp LP; College Station, TX, USA) and Excel plug-in (Daniel's XL Toolbox, version 4.01; Daniel Kraus, Boston, MA, USA), the level of significance being set at $<0.05$.

\section{RESULTS}

Of the 39 patients evaluated, 37 (94.8\%) were female and $2(5.2 \%)$ were male. Patient ages ranged from 18 to 82 years, with a mean age of $52 \pm 13$ years. There were 10 patients $(25.64 \%)$ in the young adult group $(<40$ years of age), $18(46.16 \%)$ in the adult group (40-60 years of age), and $11(28.20 \%)$ in the elderly group (> 60 years of age).

All 39 examinations presented radiological changes. A total of 14 diagnoses were made, the most prevalent rectocele (Figure 2, shown during evacuation), which was observed in 30 patients (77\%). A diagnosis of enterocele was established in 15 patients $(38.40 \%)$, the same being true for contrast retention after evacuation. Rectal prolapse was identified in 13 patients $(33.30 \%)$ and puborectalis muscle flaccidity was identified in an equal number of patients. Posterior rectocele was identified in 10 patients $(25.60 \%)$. Other diagnoses were enterocele with compressive effect on the rectum, dyskinesia of the posterior wall of the rectum, puborectalis muscle hypertonia, fecal incontinence, vaginal prolapse, fecal incontinence, uterine prolapse, hemorrhoid, and Meckel's diverticulum. These findings are presented in Table 1 .

Quantitative variations among the groups are listed in Table 2. Emptying of the rectal ampulla was the only quantitative marker that showed significant variance among the age groups, being $54 \pm 25$ in the young adult group, $79 \pm$ 12 in the adult group, and $74 \pm 11$ the elderly group $(\mathrm{p}<$
Table 1-Principal diagnoses made by defecography in the population studied.

\begin{tabular}{lcc}
\hline Diagnosis & N & $\%$ \\
\hline Anterior rectocele & 31 & 79.50 \\
Enterocele & 15 & 38.40 \\
Contrast retention after evacuation & 15 & 38.40 \\
Rectal prolapse & 13 & 33.30 \\
Puborectalis muscle flaccidity & 13 & 33.30 \\
Posterior rectocele & 10 & 25.60 \\
Enterocele with compressive effect on the rectum & 7 & 18.00 \\
Dyskinesia of the posterior wall & 4 & 10.25 \\
Puborectalis muscle hypertonia & 2 & 5.12 \\
Fecal incontinence & 2 & 5.12 \\
Vaginal prolapse & 1 & 2.56 \\
Uterine prolapse & 1 & 2.56 \\
Hemorrhoid & 1 & 2.56 \\
Meckel's diverticulum & 1 & $2 ., 56$ \\
\hline
\end{tabular}

$\mathrm{N}$, number of patients.

$0.01)$. Other lengths and angles did not vary significantly among the groups $(\mathrm{p}>0.05)$.

\section{DISCUSSION}

Imaging studies play an important role in the evaluation of diseases of the digestive system, as has been demonstrated in several recent studies conducted in Brazil ${ }^{(7-15)}$. In the present study, the majority of patients undergoing defecography were female and were between 18 and 82 years of age. Among the imaging findings, anterior rectocele was the most prevalent and emptying of the rectal ampulla was a significant quantitative marker.

It is important that each treatment facility standardize its technique for carrying out the examination, formulating protocols that include taking a full patient history, using well located and standardized markers, and taking accurate measurements in order to prevent diagnostic misinterpretations.

There is considerable variation in the values that are considered normal for each parameter, depending on the method employed by each examiner, and those values must always be interpreted in conjunction with the clinical data ${ }^{(1)}$. Of the 39 patients evaluated, $37(94.8 \%)$ were female and $2(5.2 \%)$ were male. The higher prevalence in women was expected and was previously reported by Sobrado et al. ${ }^{(16)}$.

One finding that called our attention was that $100 \%$ of the examinations presented alterations. That indicates, indirectly, that the methods employed correctly indicated the need for the examinations; that is, that the examinations were performed in individuals who were truly ill. Anterior rectocele was the diagnosis that was most prevalent in all of the patient subgroups, and we found that the changes of the pelvic floor were more related to multiple associated disorders, parity, and prior disease than to the age of the patient, as was also observed in the study conducted by Santos et al. ${ }^{(17)}$.

Other common findings were enterocele, contrast retention after evacuation, puborectalis muscle flaccidity, and pos- 
Table 2-Quantitative analysis of defecography examinations, by age group.

\begin{tabular}{|c|c|c|c|c|c|}
\hline & \multirow[b]{2}{*}{ Total } & \multicolumn{3}{|c|}{ Age group } & \multirow[b]{2}{*}{$P$} \\
\hline & & Young adult & Adult & Elderly & \\
\hline \multicolumn{6}{|l|}{ Anorectal angle $\left({ }^{\circ}\right)$} \\
\hline At rest & $102 \pm 24$ & $114 \pm 28$ & $94 \pm 21$ & $103 \pm 19$ & 0.09 \\
\hline Contraction & $83 \pm 21$ & $91 \pm 13$ & $77 \pm 25$ & $86 \pm 19$ & 0.20 \\
\hline Valsalva maneuver & $97 \pm 24$ & $100 \pm 28$ & $91 \pm 22$ & $105 \pm 21$ & 0.21 \\
\hline Evacuation & $122 \pm 22$ & $119 \pm 24$ & $118 \pm 22$ & $133 \pm 15$ & 0.09 \\
\hline \multicolumn{6}{|l|}{ Perineal descent (cm) } \\
\hline At rest (length) & $4.0 \pm 1.9$ & $3.2 \pm 1.1$ & $4.2 \pm 1.6$ & $4.3 \pm 3.3$ & 0.41 \\
\hline Contraction (length) & $3.0 \pm 2.1$ & $2.2 \pm 1.9$ & $3.3 \pm 2.0$ & $3.5 \pm 2.7$ & 0.37 \\
\hline Valsalva maneuver (length) & $5.5 \pm 2.4$ & $5.8 \pm 3.1$ & $5.1 \pm 1.9$ & $5.7 \pm 2.6$ & 0.71 \\
\hline Evacuation (length) & $7.7 \pm 2.0$ & $8.4 \pm 1.1$ & $7.4 \pm 2.3$ & $7.5 \pm 2.3$ & 0.45 \\
\hline \multicolumn{6}{|l|}{ Puborectalis muscle $(\mathrm{cm})$} \\
\hline At rest & $20 \pm 5$ & $20 \pm 5$ & $20.9 \pm 3.7$ & $19.8 \pm 5.8$ & 0.79 \\
\hline Contraction & $19 \pm 5$ & $19 \pm 6$ & $20.4 \pm 4.1$ & $19.6 \pm 5.8$ & 0.77 \\
\hline Valsalva maneuver & $21 \pm 4$ & $21 \pm 3$ & $20.9 \pm 3.9$ & $21.1 \pm 4.1$ & 0.99 \\
\hline Evacuation & $20 \pm 5$ & $19 \pm 6$ & $21.1 \pm 3.6$ & $19.3 \pm 5.4$ & 0.56 \\
\hline \multicolumn{6}{|l|}{ Length of the anal canal $(\mathrm{cm})$} \\
\hline At rest & $4.6 \pm 1.3$ & $4.5 \pm 1.2$ & $4.7 \pm 1.0$ & $4.5 \pm 1.8$ & 0.89 \\
\hline Contraction & $6.1 \pm 1.6$ & $6.1 \pm 2.0$ & $6.2 \pm 1.6$ & $5.8 \pm 1.3$ & 0.81 \\
\hline Valsalva maneuver & $3.7 \pm 1.6$ & $3.2 \pm 1.9$ & $3.9 \pm 1.6$ & $3.8 \pm 1.2$ & 0.94 \\
\hline Evacuation & $2.4 \pm 1.2$ & $2.6 \pm 1.4$ & $2.6 \pm 1.4$ & $2.5 \pm 1.0$ & 0.97 \\
\hline \multicolumn{6}{|l|}{ Opening of the anal canal $(\mathrm{cm})$} \\
\hline At rest & $0.9 \pm 0.4$ & $0.9 \pm 0.3$ & $1.0 \pm 0.3$ & $0.9 \pm 0.5$ & 0.72 \\
\hline Contraction & $0.7 \pm 0.3$ & $0.7 \pm 0.3$ & $0.8 \pm 0.2$ & $0.7 \pm 0.4$ & 0.57 \\
\hline Valsalva maneuver & $0.9 \pm 0.5$ & $0.8 \pm 0.2$ & $1.0 \pm 0.5$ & $1.1 \pm 0.6$ & 0.35 \\
\hline Evacuation & $1.4 \pm 0.4$ & $1.4 \pm 0.4$ & $1.3 \pm 0.4$ & $1.3 \pm 0.3$ & 0.76 \\
\hline Emptying of the rectal ampulla (\%) & $70 \pm 20$ & $54 \pm 25$ & $79 \pm 12$ & $74 \pm 11$ & 0.001 \\
\hline
\end{tabular}

terior rectocele. All of these diagnoses have a direct effect on patient quality of life. Unlike the physical examination, defecography allows early diagnosis of multiple dysfunctions of the pelvic floor, which completely changes the surgical $\operatorname{approach}^{(17)}$.

In the present study, the quantitative analysis showed little variance among age groups, only emptying of the rectal ampulla being significant $(p<0.05)$.

We believe that quantification in medical imaging is of the utmost importance. In the present study, the data demonstrate that disturbances of evacuation do not depend on age group alone; such disturbances mainly depend on the degree of pelvic floor dysfunction, with or without the involvement of multiple compartments. Multiparous women with dystocia tend to show findings that are much worse than would be expected simply as a result of advancing age, as was also observed by Sobrado et al. ${ }^{(16)}$ and Santos et al. ${ }^{(17)}$.

\section{CONCLUSION}

Although defecography is performed more often in women, both genders can benefit from the test. Defecography can be performed in order to detect complex disorders such as uterine and rectal prolapse, as well as to detect basic clinical conditions such as rectocele or enterocele.

\section{Acknowledgments}

We are grateful to the clinical and surgical staff of Hospital Vivalle (D’Or/São Luiz Network) in São José dos Campos, Brazil, as well as to all attending physicians who refer their patients to the Unidade de Radiologia Clínica (URC) for evaluation by defecography.

\section{REFERENCES}

1. Sobrado CW, Pires CEF, Amaro E, et al. Videodefecografia: aspectos técnicos e atuais. Radiol Bras. 2004;37:283-5.

2. Mahieu P, Pringot J, Bodart P. Defecography: I. Description of a new procedure and results in normal patients. Gastrointest Radiol. 1984;9:247-51

3. Roos JE, Weishaupt D, Wildermuth S, et al. Experience of 4 years with open MR defecography: pictorial review of anorectal anatomy and disease. Radiographics. 2002;22:817-32.

4. Faccioli N, Comai A, Mainardi P, et al. Defecography: a practical approach. Diagn Intervent Radiol. 2010;16:209-16.

5. Karasick S, Karasick D, Karasick SR. Functional disorders of the anus and rectum: findings on defecography. AJR Am J Roentgenol. 1993;160:777-82.

6. Cesar MAP, Klug WA, Aguida HAC, et al. Alterações das pressões anais em pacientes constipados por defecação obstruída. Rev Bras Coloproctol. 2008;28:402-8.

7. Rocha EL, Pedrassa BC, Bormann RL, et al. Abdominal tuberculosis: a radiological review with emphasis on computed tomography 
and magnetic resonance imaging findings. Radiol Bras. 2015;48: 181-91.

8. Teixeira VL, Santana Júnior PJ, Teixeira KISS, et al. Gastric Kaposi's sarcoma. Radiol Bras. 2015;48:196-7.

9. Gava P, Melo ASA, Marchiori E, et al. Intestinal and appendiceal paracoccidioidomycosis. Radiol Bras. 2015;48:126-7.

10. Vermelho MBF, Correia AS, Michailowsky TCA, et al. Abdomina alterations in disseminated paracoccidioidomycosis: computed tomography findings. Radiol Bras. 2015;48:81-5.

11. Queiroz RM, Botter LA, Gomes MP, et al. Enteroenteric intussusception in an adult caused by an ileal angiomiolipoma. Radiol Bras. 2015;48:339-40.

12. Mançano AD, Siqueira CC, Macedo GG. Giant colonic lipoma Radiol Bras. 2015;48(1):ix-xi.
13. Kierszenbaum ML, von Atzingen AC, Tiferes DA, et al. CT colonography: the value of this method in the view of specialists. Radiol Bras. 2014;47:135-40.

14. Barros RHO, Penachim TJ, Martins DL, et al. Multidetector computed tomography in the preoperative staging of gastric adenocarcinoma. Radiol Bras. 2015;48:74-80.

15. Cruz CLP, Fernandes GL, Natal MRC, et al. Urachal neoplasia: a case report. Radiol Bras. 2014;47:387-8.

16. Sobrado CW, Pires CEF, Araújo SEA, et al. Computerized videodefecography versus defecography: do we need radiographs? Sao Paulo Med J. 2005;123:105-7.

17. Santos JEM, D'Ippolito G, Leme LM, et al. Avaliação do ângulo anorretal por meio de defecografia em voluntárias assintomáticas nulíparas e multíparas. Radiol Bras. 2003;36:219-24. 